\title{
Paciente con complicación poco frecuente de arteritis de células gigantes
}

Rare complication in a patient with giant cell arteritis

\author{
S. Olivera' ${ }^{1}$, B. Amores ${ }^{2}$, M.A. Torralba ${ }^{2}$, J.I. Pérez Calvo²
}

\section{RESUMEN}

La arteritis de células gigantes (arteritis de la arteria temporal) es una vasculitis crónica que afecta mayoritariamente a personas de edad avanzada. Aunque se trata de una enfermedad sistémica, se afectan sobre todo las arterias craneales. La complicación más frecuente de esta patología es la pérdida visual. Presentamos el caso clínico de una paciente que padeció varias complicaciones, entre ellas una necrosis lingual, a raíz de serle diagnosticada una arteritis de células gigantes tras iniciar el tratamiento de la misma.

Palabras clave. Arteritis. Células-gigantes. Necrosis lingual. Ictus

\begin{abstract}
Giant cell arteritis (temporal arteritis) is a chronic vasculitis that usually affects older people. Although this is a systemic disease, it most often affects the cranial arteries. The most frequent complication of this disorder is visual loss. We report the case of a patient who suffered several rare complications, including tongue necrosis, as a result of being diagnosed with giant cell arteritis following the start of treatment.
\end{abstract}

Key words. Arteritis. Giant-cell. Tongue necrosis. Stroke
1. Servicio de Medicina Interna. Hospital de Denia. Alicante

2. Hospital Clínica Universitario "Lozano Blesa». Zaragoza

Recepción: 25 de agosto de 2010

Aceptación provisional: 29 de septiembre de 2010

Aceptación definitiva: 2 de noviembre de 2010

\section{Correspondencia}

Susana Olivera González

Servicio de Medicina Interna

Hospital de Denia. Alicante

E-mail: susana.olivera@yahoo.es 


\section{INTRODUCCIÓN}

La arteritis de células gigantes es una vasculitis crónica que afecta a vasos de mediano y gran calibre. Se da a edad avanzada $\mathrm{y}$, prácticamente, nunca se diagnostica por debajo de los cincuenta años. Aunque se trata de una enfermedad sistémica, la inflamación vascular afecta mayoritariamente a las arterias craneales que se originan del arco aórtico. La complicación más frecuente de esta patología es la pérdida visual ${ }^{1}$.

Las manifestaciones clínicas suelen aparecer de forma gradual, aunque la presentación brusca ocurre en algunos pacientes. Aparecen síntomas sistémicos como fiebre, astenia y pérdida de peso. En dos tercios de los pacientes hay cefalea de nueva aparición, que suele localizarse en la región temporal y que constituye el síntoma más frecuente. La cefalea empeora de forma nocturna y, a veces, se agrava con la exposición al frío. En la mitad de los pacientes existe claudicación mandibular, que es el síntoma más específico. Pueden aparecer una variedad de síntomas visuales y, en la mayoría de los casos, se trata de una amaurosis fugax, causada por una isquemia transitoria de la retina, coroides, nervio óptico o combinación de ellas. La complicación más grave es la ceguera uni o bilateral, debido a neuropatía óptica isquémica (infarto del nervio óptico). En casi la mitad de los pacientes con arteritis de células gigantes aparece también polimialgia reumática. Pueden aparecer otros síntomas del tracto músculo-esqueléticos, del tracto respiratorio superior (como tos persistente no productiva), claudicación de extremidades superiores, aneurisma aórtico, disección aórtica, afectación del sistema nervioso central (accidente cerebro-vascular), dolor de garganta, tumoraciones mamarias, síndrome de secreción inadecuada de hormona antidiurética, mononeuritis múltiple, pérdida auditiva sensitiva, disartria, isquemia mesentérica y dolor lingual ${ }^{1,2}$.

La velocidad de sedimentación globular (VSG) suele estar elevada, pero una VSG normal no excluye la arteritis de células gigantes. El diagnóstico se realiza fundamentalmente por la clínica y se confirma mediante la biopsia de la arteria temporal, donde se observa una vasculitis de células gigantes. El tratamiento de elección son los corticoides a altas dosis, en ocasiones asociados a azatioprina o metotrexate ${ }^{1,2}$.

Presentamos el caso clínico de una paciente que presentó una complicación poco frecuente de una arteritis de células gigantes, a pesar de haber iniciado el tratamiento de dicha vasculitis.

\section{CASO CLÍNICO}

Presentamos el caso clínico de una mujer de 74 años, sin alergias conocidas y con antecedentes médicos de bronquitis asmática, hipertensión arterial, portadora de marcapasos (desde hacía 5 años), e intervenida quirúrgicamente de prótesis valvular mitral (hacía 3 años) y cáncer de mama (dieciocho años antes). Seguía tratamiento habitual con acenocumarol, furosemida, bisoprolol, espironolactona, enalapril, pantoprazol y hierro oral. La paciente refería clínica de tres meses de evolución de cefalea occipital unilateral, irradiada a zona frontal y temporal, de tipo opresivo, que no cedía con analgésicos habituales y acompañada de astenia, hiporexia, pérdida ponderal de $10 \mathrm{Kg}$ y claudicación mandibular intermitente. A la exploración física, destacaba palidez de mucosas. No se palpaban adenopatías. En el resto de la exploración física no se encontraron otros hallazgos significativos. La exploración neurológica fue normal. Se solicitaron como pruebas complementarias analítica de sangre y tomografía computarizada (TC) craneal. En la analítica no existía anemia y sí leucocitosis con neutrofilia. Asimismo se observó una glucemia de $128 \mathrm{mg} / \mathrm{dl}$. La PCR fue de 3’99 mg/ dl. La velocidad de sedimentación globular (VSG) fue de $83 \mathrm{~mm}$ (en la $1^{\mathrm{a}}$ hora). No se observaron otras alteraciones analíticas. En la TC craneal no se observaron lesiones ocupantes de espacio y sí una hiperostosis cortical frontoparietal interna. Con la sospecha inicial de arteritis de la arteria temporal, se inició tratamiento corticoideo con metilprednisolona a la dosis de $1 \mathrm{mg} / \mathrm{Kg}$ vía oral, mejorando la clínica inicial. Tres días después se realizó biopsia de la arteria temporal, confirmándose el diagnóstico anatomopatológico. A las cuarenta y ocho horas de dicha biopsia, la paciente refiere dolor intenso en la lengua, con aparición de lesión ulcerada en hemilengua derecha (Fig. 1), realizándose cultivos microbiológicos, siendo negativos, TC cervical, donde se observaba tumoración de hemilengua derecha sin adenopatías y una biopsia de la misma, con el resultado de necrosis de coagulación de etiología isquémica. La paciente evolucionó favorablemente, resolviéndose la lesión lingual espontáneamente, siendo dada de alta, para realizar seguimiento y control de la evolución y el tratamiento en consultas externas. 


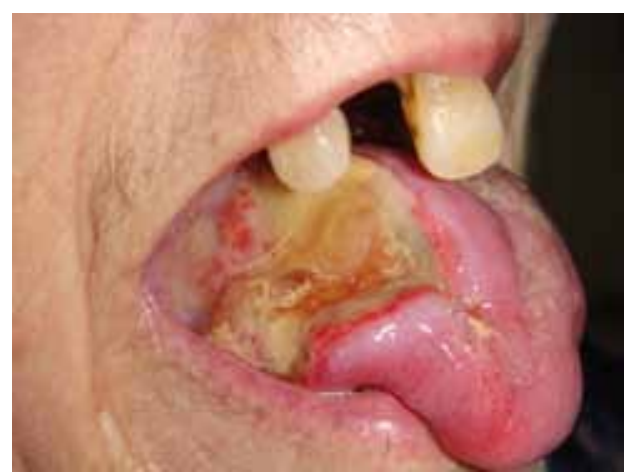

Figura 1. Necrosis lingual (imagen macroscópica).

Dos meses después, la paciente acude a urgencias por debilidad en hemicuerpo derecho y alteración del lenguaje. A la exploración física la paciente presentaba hemiparesia derecha (balance motor de extremidad superior 3-/5 y extremidad inferior de 2/5), afasia global, paresia facial derecha y hemianopsia homónima derecha. En la TC craneal se observa un extenso infarto agudo isquémico en el territorio de la arteria cerebral media y arteria cerebral posterior izquierdas (Fig. 2). En el electrocardiograma se observaba ritmo de marcapasos. En el estudio de coagulación, destacaba un INR de 1'48. No se realizaron otras pruebas complementarias como angiorresonancia magnética (RM) cerebral, ecografía-doppler transcraneal y de troncos supraaórticos, ni ecocardiograma (transtorácico ni transesofágico). La paciente fue remitida a un centro de larga estancia para realización de rehabilitación intensiva.

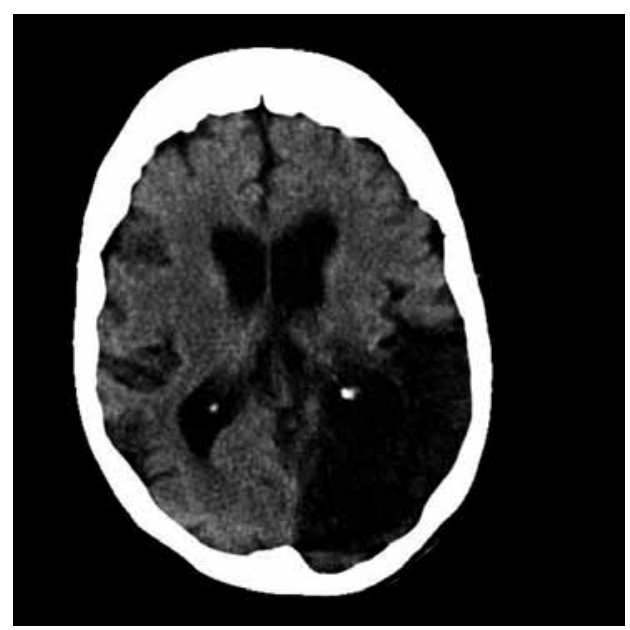

Figura 2. TC cerebral: infarto agudo en el territorio de las arterias cerebrales media y posterior izquierdas.

\section{DISCUSIÓN}

La necrosis lingual es una rara complicación de la arteritis de células gigantes. Ocurre generalmente por la estenosis y oclusión de las arterias linguales. El dolor lingual, así como su claudicación, son signos que nos han de hacer pensar en una isquemia lingual para así no permitir que ésta progrese hacia la necrosis ${ }^{3,4}$.

Ante un paciente anciano con dolor intenso a nivel lingual ha de pensarse en esta complicación. La lesión de la arteria lingual no es un hallazgo anatomopatológico excepcional, pero sí que la isquemia se manifieste clínicamente a nivel lingual debido a su rica vascularización ${ }^{5-9}$.

La mayoría de los casos aparecen en mujeres mayores de 70 años y los síntomas de la isquemia lingual suelen preceder en días o semanas a la aparición de la necrosis de la lengua. Dentro de los factores que pueden favorecer la isquemia a nivel lingual están la administración de ergotamínicos, macrólidos, infiltración de anestésicos locales, extracciones dentales o cualquier otra causa de reducción del flujo sanguíneo previamente alterado por la vasculitis ${ }^{5-9}$.

La necrosis lingual, una vez que aparece, afecta de forma bilateral a la lengua en la mitad de los pacientes. En el $20 \%$ de los pacientes se afecta el dorso lingual y en el $25 \%$ solamente la punta de la lengua ${ }^{5-9}$.

En el caso de nuestra paciente, se afectó la lengua de forma unilateral. No existían factores de riesgo que predispusieran al desarrollo de la necrosis lingual. Además, en nuestra paciente la necrosis lingual se produjo tras el diagnóstico clínico de la arteritis de células gigantes y el inicio del tratamiento con corticoides. Tampoco habían existido síntomas premonitorios previos a la aparición de la lesión lingual. En la mayoría de las publicaciones consultadas se describe la necrosis lingual como síntoma previo al diagnóstico de la arteritis de células gigantes antes de iniciar un tratamiento adecuado. Además, también a diferencia de nuestra paciente, se describe como más frecuente la afectación bilateral de la lengua $^{3-9}$. 
Nuestra paciente, posteriormente, presentó un accidente cerebrovascular isquémico extenso, a pesar de seguir tratamiento con acenocumarol de forma crónica. No se realizaron pruebas complementarias distintas a la TC craneal para filiar la etiología de dicho ictus. Dada la cardiopatía previa de la paciente, sería acertado suponer que la causa fue cardioembólica aunque, debido a la edad de la paciente y otros factores de riesgo cardiovascular, no pueda descartarse una etiología aterotrombótica. Sería interesante discutir el papel que puede jugar la existencia de una vasculitis. Se ha documentado un aumento en la incidencia de ictus, sobre todo en el territorio vértebro-basilar más que en el carotídeo, en pacientes con arteritis de células gigantes, sobre todo en los 5 primeros años que siguen al diagnósti$\mathrm{co}^{10}$. No se conoce exactamente si es por la aterosclerosis, la inflamación vascular persistente o la iatrogenia de los corticoides, aunque parece ser que la causa de estos eventos es la persistencia de la inflamación vascular $^{11}$. Además, se ha visto que existe un riesgo incrementado en el caso de pacientes con otros factores de riesgo cardiovascular así como un efecto protector potencial en el caso de que exista anemia ${ }^{12}$.

Es importante conocer el riesgo incrementado de isquemia cerebral para poder realizar una profilaxis primaria ya que, como se ha descrito, ésta puede disminuir la incidencia de eventos isquémicos vasculares cerebrales ${ }^{13-14}$.

En resumen, en pacientes con arteritis de la arteria temporal se pueden producir, aunque de forma infrecuente, complicaciones raras como la necrosis lingual y otras más graves como ictus. Es importante conocer estas posibles complicaciones para realizar una adecuada profilaxis mediante la terapia con corticoides y anticoagulantes orales, sobre todo en pacientes con otros factores de riesgo cardiovascular.

\section{BIBLIOGRAFÍA}

1. Raskin NH. Cefalalgia. En: Harrison's Principles Internal Medicine, $16^{\mathrm{a}} \mathrm{Ed}$. México DF, McGraw-Hill, 2006: 98-108.
2. CASAs JM, Acha MV. Etiopatogenia de la arteritis de células gigantes. An Sist Sanit Navar 2003; 26: 43-61.

3. Husein-Elahmed H, Callejas-Rubio JL, Ríos-FerNÁNDEZ R, ORTEGo-CEnTENo N. Tongue infarction as first symptom of temporal arteritis. Rheumatol Int 2010. (En prensa).

4. Brodmann M, Dorr A, Hafner F, Gary T, Pilger E. Tongue necrosis as first symptom of giant cell arteritis (GCA). Clin Rheumatol 2009; 28 (Suppl. 1): S47-S49.

5. Goicoechea M, Correale J, Bonamico L, Domínguez R, BAgG E, FAmulari A et al. Tongue necrosis in temporal arteritis. Headache 2007; 47: 1213-1215.

6. Zimmermann AT, Brown M. Tongue infarction in giant cell (temporal) arteritis. Intern Med J 2008; 38: 376.

7. MAAHS GS, FABRICIO DD. Tongue necrosis in a patient with cranial arteritis. Braz J Otorhinolaryngol 2007; 73: 717.

8. Kusanale A, Boardman H, Khoshnaw H. Tongue necrosis: a rare presentation of temporal arteritis. Age Ageing 2008; 37: 119.

9. Monerris-García E, Polo-Tomás I, Ortega-Pastor E, FERnández-PÉrez AJ. Tongue necrosis as onset of temporal arteritis. Acta Otorrinolaringol Esp 2003; 54: 74-77.

10. Crow RW, Katz BJ, Warner JE, Alder SC, Zhang $\mathrm{K}$, Schulman $\mathrm{S}$ et al. Giant cell arteritis and mortality. J Gerontol A Biol Sci Med Sci 2009; 64: 365-369.

11. Fitzgerald AJ, Ironside JW, Summers DM, DenNIS MS, McRorIE ER. Two cases of recurrent stroke in treated giant cell arteritis: diagnostic and therapeutic dilemmas. J Clin Rheumatol 2010; 16: 225-228.

12. GonzÁlez-Gay MA, VÁZquez-RodríGuez TR, Gómez-Acebo I, Pego-Reigosa R, LóPez-Díaz MJ, VÁZQUEZ-TRIÑANES MC et al. Strokes at time of disease diagnosis in a series of 287 patients with biopsy-proven giant cell arteritis. Medicine 2009; 88: 227-235.

13. Solans-Laqué R, Bosch-Gil JA, Molina-Catenario CA, Ortega-Aznar A, Álvarez-Sabin J, VilardellTARRES M et al. Stroke and multi-infarct dementia as presenting symptoms of giant cell arteritis: report of 7 cases and review of the literatura. Medicine 2008; 87: 335-344.

14. Lee MS, Smith SD, Galor A, Hoffman GS. Antiplatelet and anticoagulant therapy in patients with giant cell arteritis. Arthritis Rheum 2006; 54: 3306-3309. 